\title{
Covid-19, Anosmia, Ageusia: Prospective Observational Study, Follow-Up Three and Eight Months Later
}

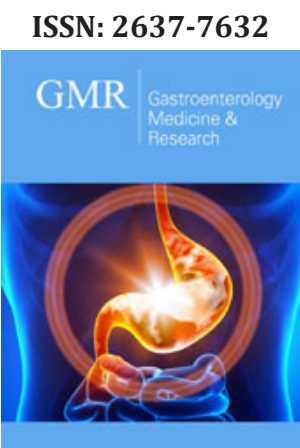

*Corresponding author: Yordan Benhamou, Odontology Department, Saint Roch Hospital, 5 rue Pierre Dévoluy, Nice University Hospital Center, 06000 Nice, France

Submission: 侮 January 04, 2021

Published: 战January 25, 2021

Volume 5 - Issue 3

How to cite this article: Yordan Benhamou, Adeline Morisot, Isabelle Prêcheur. Covid-19, Anosmia, Ageusia: Prospective Observational Study, FollowUp Three and Eight Months Later. Gastro Med Res. 5(3). GMR. 000615. 2021.

DOI: 10.31031/GMR.2021.05.000615

Copyright@ Yordan Benhamou, This article is distributed under the terms of the Creative Commons Attribution 4.0 International License, which permits unrestricted use and redistribution provided that the original author and source are credited.

\author{
Yordan Benhamou ${ }^{1,2 *}$, Adeline Morisot ${ }^{3}$ and Isabelle Prêcheur ${ }^{1,2}$ \\ ${ }^{1}$ University of Côte d'Azur, Faculty of Dental Surgery, MICORALIS EA 7354 laboratory, Nice, \\ France \\ ${ }^{2}$ University of Côte d'Azur, Nice University Hospital Center, Department of Odontology, Nice, \\ France \\ ${ }^{3}$ University of Côte d'Azur, Nice University Hospital Center, Department of Public Health, Nice, \\ France
}

\begin{abstract}
Objectives: Sudden loss of smell (anosmia) and taste (ageusia) are common symptoms in benign to moderate forms of Coronavirus Disease (COVID-19). Many patients recover normal function within two weeks, but some suffer from prolonged abnormalities. This study aimed to identify subjective persistent smell and taste alterations several months after the disease onset.
\end{abstract}

Subjects and methods: This prospective observational study consisted in online questionnaires addressed to outpatients diagnosed for COVID-19 during the first wave in France, three months and eight months later.

Results: Among 80 participants, 79\% self-reported anosmia (mean duration 12 days) and 73\% ageusia (13 days). Anosmia was associated with Body Mass Index (BMI) $>25$. Three months later, at least 18\% and $16 \%$ of participants had not fully recovered olfaction and taste. Initial anosmia/ageusia episode was $>3$ weeks. At least $5 \%$ reported persistent alterations for more than eight months. Olfactory disturbances were parosmia (distorted odour perception) and phantosmia, with ghost smell such as strong smells of cooking and cold tobacco, nasal stinging, chemical and moldy sensations. Taste disturbances were gustatory and chemesthesis alterations and food disgust (carrots, meat).

Conclusion: Persistent anosmia and ageusia can lead to nutrition disorders and depression, and should be monitored after a COVID-19 episode

Keywords: Anosmia; COVID-19;Ageusia;Parosmia; Phantosmia; SARS-CoV-2

\section{Introduction}

The Severe Acute Respiratory Syndrome-Coronavirus-2 (SARS-CoV-2) is responsible for the current pandemic of coronavirus disease (COVID-19). The virus is mainly excreted in saliva and respiratory secretions, and it is easily transmitted by air (droplets), contaminated hands or surfaces. The incubation period is on average 5 days (2-14 days) and infected persons are contagious 1-2 days before clinical symptom onset. After clinical healing, oralpharyngeal carriage of SARS-CoV-2 can last a very long time, 20 to 25 days [1]. Airborne transmission and high resistance in the outside environment contribute to the very rapid spread of the virus and the severity of the 2019-2020 pandemic [2].

The SARS-CoV-2 enters human cells via abiding of viral spike (S) protein on a human surface receptor, the type 2 angiotensin conversion enzyme (ACE2). Viral entry needs viral protease activity, mainly transmembrane protease serine 2 (TMPRSS2) or eventually cathepsin B/L. ACE2 is present on the surface of endothelial cells, and many other cells in the lower (lung) and upper respiratory tract (nasal epithelium), heart, brain, intestines, liver, kidneys, testicles, cornea and salivary glands [3]. Infection ranges from asymptomatic to mild (about $50 \%$ of infected subjects), moderate, or severe. Pneumonia can evolve to acute respiratory distress, multi-organ failure and death. Main risk factors include age $>65$, male gender, obesity, pre-existing hypertension, cardiovascular disease, chronic obstructive pulmonary disease and diabetes [4]. The most common symptoms of COVID-19 are fever, 
chills, dry cough, dyspnea, diarrhea, headache, unusual fatigue, alteration of the general state. Sudden loss of smell (anosmia) or taste (ageusia) occurs in approximately $60 \%$ of mild to moderated forms of COVID-19, and regresses within a few weeks [5-7]. Some patients may have myalgia, nasal congestion, runny nose, or other symptoms: cardiac (myocarditis), digestive (anorexia, vomiting), renal (proteinuria, microscopic haematuria), dermatologic (peripheral vascular disease), and neurologic [8].

Anosmia is defined as the loss of or impaired ability to smell. Anosmia may be caused by neurologic diseases or trauma, paranasal sinus diseases, smoking or viral infections of the respiratory tract [9]. Olfaction is provided by the olfactory epithelium, which is located in the upper nasal cavity in the olfactory cleft. This epithelium contains olfactory neurons, support cells and basal cells (progenitor/stem cells). Olfactory neurons have a ciliated end in contact with the nasal mucus, which carries receptors for odorous molecules. The axon passes through the cribriform plate of the ethmoid to reach the olfactory bulb. Axons from several neurons converge and form the olfactory nerve $\left(1^{\text {st }}\right.$ pair of cranial nerves or I), which is very short and consists of many nerve threads [10]. Olfactory neurons do not express ACE2 and TMPRSS2, and it is still unclear if SARS-CoV-2 can infect human neurons [11]. However, sustentacular cells in the human olfactory neuroepithelium express high levels of ACE2 and TMPRSS2. Four mechanisms may explain anosmia: runny nose and nasal obstruction (not regularly observed in COVID-19), microvascular injury of olfactory bulb, impairment of the olfactory cortical areas in the brain (does not explain the rapid onset of anosmia) and viral infection and damage to support cells [12]. In addition to inhibition of odour perception cascade, viral infection induces a rapid immune response in the olfactory epithelium. Lymphocytes and macrophage infiltration and secretion of pro-inflammatory cytokines lead to olfactory cleft inflammation and obstruction. This prevents volatile chemicals from reaching the olfactory epithelium [13]. Ageusia is a complete or severe loss of the subjective sense of taste, frequently accompanied by olfaction disorders [9]. Taste is conveyed by taste buds, which are present mainly on the tongue then by the soft palate, pharynx and other oro-pharyngeal mucous membranes. Co-expression of ACE2 and TMPRSS2 proteins in taste buds is controversial [3,14]. Taste buds contain gustatory neurons, support cells and basal cells. In taste buds, gustatory neurons are closely associated with partner neurons specialized in sensorimotor signals perception. Four pairs of cranial nerves are involved in oral perception of taste: the trigeminal $\left(\mathrm{V}_{2}\right.$ maxillary root and $\mathrm{V}_{3}$ mandibular root), facial (VII sensory root), glossopharyngeal (IX) and vagus (X) nerves. Schematically, gustatory neurons ensure the perception of taste stricto sensu, which includes the perception of five basic stimuli: sweet, bitter, acid, salty and umami (VII sensory root, IX and X). Some partner neurons perceive chemosensory stimuli, i.e. pungent stimuli (garlic, radishes, alcohol, bubbles, etc.) and astringent stimuli (plant tannins, wine) $\left(\mathrm{V}_{3}\right)$. Other partner neurons perceive heat, cold, tact, pain $\left(\mathrm{V}_{2-3}\right.$, IX and $\left.\mathrm{X}\right)$, or temporomandibular proprioception $\left(\mathrm{V}_{2-3}\right)$. Olfactory neurons (I) are the only ones that can capture aromatic molecules, which are volatile, and contribute to taste perception. This is why anosmia prevents food aroma perception. The final sensation of taste is influenced by complex and redundant stimulations of the five senses and memory $[10,15]$.

Viral anosmia and ageusia are usually temporary, as the olfactory and gustative neurons have a lifespan of about ten days and they renew very quickly from the basal cells and from preexisting immature neurons. Support cells regenerate faster than mature neurons [10]. In COVID-19 approximately 25\% of patients recover normal olfactory function within 2 weeks, but $16 \%$ suffer from persistent anosmia $>6$ weeks [16]. Some rare COVID-19 patients suffer from prolonged smell disturbance, such as parosmia and phantosmia, with resulting taste abnormalities. Parosmia is a distorted odour perception in the presence of a triggering source, generally unpleasant (chemical, gasoline, burnt, rotten, foul, etc.). Phantosmia is a distorted odour perception in the absence of a triggering source (ghost smell), generally unpleasant too [17]. The aim of this study was to evaluate the prevalence and length of the orofacial subjective signs of COVID-19. Primary endpoint was the subjective report of ageusia and anosmia during the first wave of COVID-19 pandemic in France. Secondary endpoint was to identify subjective persistent smell and taste alterations three months later, and eight months later during the second wave of COVID-19 pandemic.

\section{Materials and Methods}

\section{The survey}

This survey was a prospective observational study of taste and smell alteration during the 2020 COVID-19 pandemic in France. Step 1 took place during the first lockdown (March $17^{\text {th }}$ to May $11^{\text {th }}$ ). In parallel with new scientific publications related to taste and smell alterations, we extended the study. Step 2 was completed three months later and Step 3 eight months later during the second lockdown (October $30^{\text {th }}$ to December $15^{\text {th }}$ ). For Step 1, an online questionnaire Google Forms (Google Inc.) was addressed on networks of dentists, oral surgeons and physicians for patients diagnosed for COVID-19 (Table 1). The inclusion criterion was a clinical diagnosis of COVID-19 by the referring physician or dentist. There was no exclusion criterion. All the participants or legal representative gave their consent for the study. Step 2 and Step 3 questionnaires were directly submitted to participants. The study was approved by the Nice University Hospital review board (March $30^{\text {th }}$ ), Nice, France (ClinicalTrials.gov NCT04361565) and endorses to the STROBE guidelines.

\section{Statistical analysis}

Statistical analysis was conducted by using SPSS software (Statistical Package for the Social Sciences, IBM, Chicago, Illinois). Lower, upper limits and average values with standard deviation were calculated for age and Body Mass Index (BMI: weight (kg)/ height $\left(\mathrm{m}^{2}\right)$ ) descriptive variables. Frequencies were calculated considering missing values as "missing" (supporting information on demand). To assess independence of variables, univariate crosstabs analysis was conducted using a Chi square Pearson's test. 
Sensitivity of Chi square was controlled by value of classes over 5 . If the value was inferior to 5, a Fisher test was substituted. When the loss of smell or taste was part of the first two symptoms, the subject was classified in the category "Early", otherwise in the category "Late". Multivariable analysis method and results are detailed in supporting information on demand.

Table 1: Online forms for Step 1,2 and 3.

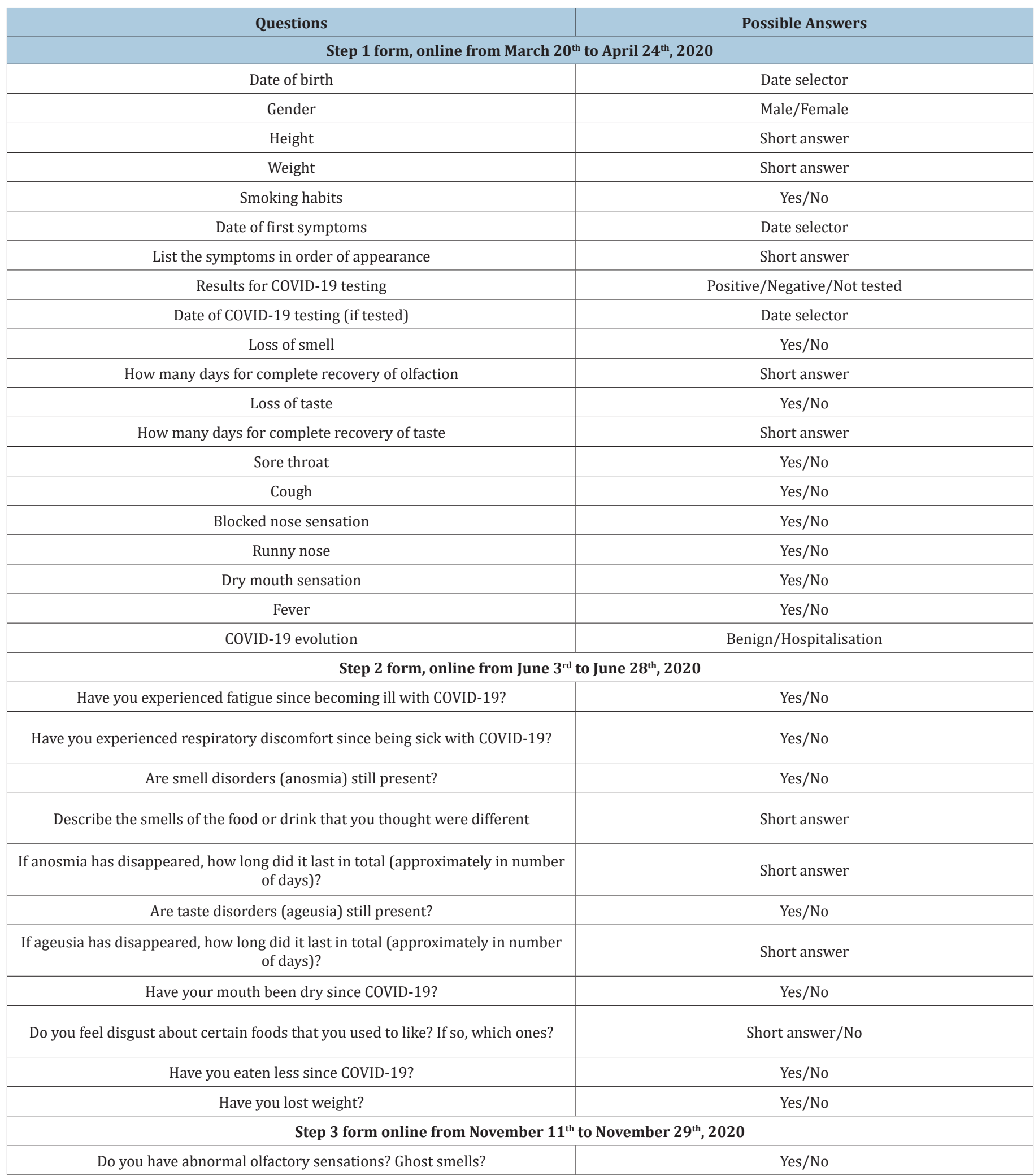




\begin{tabular}{|c|c|}
\hline If you have ghost smells, check off the smells you feel & $\begin{array}{c}\text { Skip the question, no ghost smell/ Chemical/Burning/Smoke/ } \\
\text { Rotten/Pleasant/Other smell }\end{array}$ \\
\hline Are these ghostly smells accompanied by taste disturbances? & Yes/No \\
\hline Do you still have a loss of smell for certain odours? & $\begin{array}{r}\text { Yes/No } \\
\text { If you no longer perceive certain odours check off those that are affected. } \\
\text { Burnt/Bad odours/Add an option or add "Other" }\end{array}$ \\
\hline
\end{tabular}

\section{Results and Discussion}

Eighty one participants completed Step 1 of the study. Answers are detailed in Table 2. Three participants were excluded for the age variable due to a mistake in entering the date of the day instead of date of birth. Some participants did not answer all the questions. One participant who had no anosmia, no ageusia and was tested negative of COVID-19 was excluded from multivariate analysis (supporting information on demand). Participants ranged from 15 to 68 years old, sex ratio male/female of 0.4 . Clinical evolution of COVID-19 was in most cases benign (96.3\%). Seventeen patients were tested positive and one patient negative for SARS-CoV-2. The diagnosis of COVID-19 was assessed by a physician in $77.8 \%$ of cases without testing, due to governmental instructions for not testing light to mild cases in France in March and April 2020. At this time, French authorities recommended a nasopharyngeal PCR test despite its limitations (false negatives).

Table 2: Demographic and clinical characteristics of the subjects who participated in the study. "No answer" was handled as missing data.

\begin{tabular}{|c|c|c|c|c|}
\hline & \multicolumn{2}{|c|}{ Step 1 (81 Subjects) } & \multicolumn{2}{|c|}{ Step 2 (42 Subjects) } \\
\hline & Mean or percent & $\mathrm{n} / \mathrm{N}$ & Mean or percent & $\mathrm{n} / \mathrm{N}$ \\
\hline Age, years (sd): & $37.4+/-11.7$ & $\mathrm{~N}=78$ & $38.2+/-13.3$ & $\mathrm{~N}=41$ \\
\hline 15 to $<30$ years & $33.30 \%$ & $26 / 78$ & $34.10 \%$ & $14 / 41$ \\
\hline 30 to 40 years & $34.60 \%$ & $27 / 78$ & $29.30 \%$ & Dec- 41 \\
\hline$>40$ to 68 & $32.10 \%$ & $25 / 78$ & $36.60 \%$ & $15 / 41$ \\
\hline Gender Male & $28.40 \%$ & $23 / 81$ & $23.80 \%$ & Oct- 42 \\
\hline Gender Female & $71.60 \%$ & $58 / 81$ & $76.20 \%$ & $32 / 42$ \\
\hline Body Mass Index, $\mathrm{kg} / \mathrm{m}^{2}$ (sd): & \multicolumn{2}{|c|}{$24.2+/-3.5$} & \multicolumn{2}{|c|}{$24.4+/-3.7$} \\
\hline$<21$ & $13.60 \%$ & $11 / 81$ & $9.50 \%$ & $4 / 42$ \\
\hline 21 to 25 & $51.90 \%$ & $42 / 81$ & $54.80 \%$ & $23 / 42$ \\
\hline$>25$ & $34.60 \%$ & $28 / 81$ & $35.70 \%$ & $15 / 42$ \\
\hline Tobacco smoking & $9.90 \%$ & $8 / 81$ & $2.40 \%$ & $1 / 42$ \\
\hline Early/late symptoms: early & $31.60 \%$ & $18 / 57$ & $31.40 \%$ & $11 / 35$ \\
\hline Early/late symptoms: late & $68.40 \%$ & $39 / 57$ & $68.60 \%$ & $24 / 35$ \\
\hline COVID-19 testing: not done & $77.80 \%$ & $63 / 81$ & $71.40 \%$ & $30 / 42$ \\
\hline COVID-19 testing: negative & $1.20 \%$ & $1 / 81$ & $0 \%$ & $0 / 42$ \\
\hline COVID-19 testing: positive & $21 \%$ & $17 / 81$ & $28.60 \%$ & $12 / 42$ \\
\hline Anosmia (loss of smell) & $79 \%$ & $64 / 81$ & $83.30 \%$ & $35 / 42$ \\
\hline Anosmia duration $<7 \mathrm{~d}$ & $16.70 \%$ & $6 / 36$ & $12.50 \%$ & $4 / 28$ \\
\hline Anosmia duration $>7$ to $14 \mathrm{~d}$ & $38.90 \%$ & $11 / 36$ & $29.20 \%$ & $8 / 28$ \\
\hline Anosmia duration $>14 \mathrm{~d}$ & $52.80 \%$ & $19 / 36$ & $58.30 \%$ & $16 / 28$ \\
\hline Ageusia (loss of taste) & $72.80 \%$ & $59 / 81$ & $83.30 \%$ & $35 / 42$ \\
\hline Ageusia duration $<7 \mathrm{~d}$ & $11.40 \%$ & $4 / 35$ & $10.30 \%$ & $3 / 29$ \\
\hline Ageusia duration $>7$ to $14 \mathrm{~d}$ & $28.60 \%$ & $10 / 35$ & $27.60 \%$ & $8 / 29$ \\
\hline Ageusia duration $>14 \mathrm{~d}$ & $60 \%$ & $21 / 35$ & $62.10 \%$ & $18 / 29$ \\
\hline Sore throat & $51.90 \%$ & $42 / 81$ & $47.60 \%$ & $20 / 42$ \\
\hline Cough & $64.20 \%$ & $52 / 81$ & $66.70 \%$ & $28 / 42$ \\
\hline
\end{tabular}




\begin{tabular}{|c|c|c|c|c|}
\hline Blocked nose sensation & $54.30 \%$ & $44 / 81$ & $57.10 \%$ & $24 / 42$ \\
\hline Runny nose & $43.20 \%$ & $35 / 81$ & $38.10 \%$ & $16 / 42$ \\
\hline Dry mouth sensation & $40.40 \%$ & $19 / 47$ & $41.40 \%$ & $12 / 29$ \\
\hline Fever & $45.70 \%$ & $37 / 81$ & $47.60 \%$ & $20 / 42$ \\
\hline COVID-19 evolution benign & $96.30 \%$ & $78 / 81$ & $92.90 \%$ & $39 / 42$ \\
\hline Hospitalisation & $3.70 \%$ & $3 / 81$ & $7.10 \%$ & $3 / 42$ \\
\hline Breathing difficulty & ND & ND & $28.60 \%$ & $12 / 42$ \\
\hline Fatigue & ND & ND & $42.90 \%$ & $18 / 42$ \\
\hline Loss of appetite & ND & ND & $14.30 \%$ & $6 / 42$ \\
\hline Loss of weight & ND & ND & $21.40 \%$ & $9 / 42$ \\
\hline
\end{tabular}

\section{Table Abbreviations ND: not done}

In this study, during Step 1 anosmia and ageusia were reported by $79 \%$ and $72.8 \%$ subjects, respectively. Two thirds of subjects (66.7\%) reported both anosmia and ageusia, but 16\% presented neither anosmia nor ageusia. Anosmia and/or ageusia appeared early and were described among the first two symptoms of COVID-19 for $31.6 \%$ subjects. Anosmia duration ranged from 1 to 30 days. The mean time for olfaction recovery was $11.7(+/-$ 6.4) days. Anosmia was associated with ageusia in $85.9 \%$ of participants $(\mathrm{p}=0.001)$ but $14.1 \%$ subjects reported isolated loss of smell. Participants who reported anosmia were often younger (mean age 35.9+/-10.9 vs 42.7+/-13.5; $\mathrm{p}=0.0597$ ). They also reported fewer symptoms of sore throat $(43.8 \%(28 / 64)$ vs $56.2 \%(36 / 64) ; \mathrm{p}=0.0059$ ) (supporting information on demand). Ageusia duration ranged from 6 to 45 days. The mean time for taste recovery was $12.8(+/-8)$ days. Ageusia was associated with anosmia in $93.2 \%$ of participants ( $\mathrm{p}=0.001)$, but $6.8 \%$ of subjects described isolated loss of taste. Ageusia occurred among the first two symptoms only in about $1 / 3$ of subjects and later in $2 / 3$ of cases (36.7\%(18/49) vs $63.3 \%(31 / 49) ; \mathrm{p}=0.0463)$. When the analysis is limited to the 17 subjects who had a positive COVID-19 test, $88.2 \%$ of subjects reported anosmia and $76.5 \%$ ageusia, $3 / 4(76.5 \%)$ had a combined loss of taste and smell, and about $1 / 10$ had no loss of taste or smell (11.7\%). More than $2 / 3$ of subjects with a positive test did not report a sore throat $(69.3 \%$; $\mathrm{p}=0.0294)$. Participants with early loss of smell or taste did not report systematic symptoms of high respiratory infection. Instead, they reported no sore throat (77.8\%; $\mathrm{p}=0.0478)$, no cough $(61.1 \%$; $\mathrm{p}=0.0376)$, no fever $(83.3 \%$; $\mathrm{p}=0.006)$, no dry mouth $(100 \% ; \mathrm{p}=0.0331)$ or no sign of blocked nose (tendency). Finally, the older the subjects were, the more likely they were to lose weight: $0 \%$ in the $15-30$ age group, $1 / 4(25 \%)$ in the $30-40$ age group and $1 / 3$ in the $40-68$ age group (33.3\%; $\mathrm{p}=0.049$ ).

Forty two participants who completed Step 1 also completed Step 2. Some of them considered they had not fully recovered olfaction $(17.5 \%, 14 / 80)$ and taste $(16.2 \%, 13 / 80)$ three months after COVID-19 onset. Compared to Step 1, we observed a tendency without statistical significance to more symptoms of taste and smell loss, longer symptoms of smell and taste loss, and more hospitalisations (Table 2). Conversely, there was a tendency to less tobacco smoking, sore throat and running nose. Anosmia was associated with overweight and obesity (mean BMI 27.9+/-5.3 vs 23.8+/-3.2; $\mathrm{p}=0.0464$ ). Nine participants reported persistent qualitative alterations of smell or taste (Table 3). Only nine participants completed Step 3. Eight month after COVID-19 episode, four subjects reported abnormal olfactory sensations, ghost smells and/or taste alterations $(5 \%, 4 / 80)$. Qualitative alterations were as follows: distorted smell sensations (dysosmia, case 1,7,9,10,11 and 13), ghost smells (phantosmia, case 7,8,10 and 12), distorted taste sensations (dysgeusia, case 1,2,3,4,6 and 9) and food disgusts (case 5 and 8) (Table 3). These patients (16.3\%, 13/80) suffering from persistent qualitative smell and/or taste alterations had a long anosmia and/or ageusia initial episode, with mean values of respectively $24.2+/-21.8$ days and $21.8+/-39.2$ days.

Table 3: Qualitative smell (dysosmia, phantosmia) and taste (dysgueusia) alterations three and eight months after COVID-19 episode. Participants described more or less pronounced smell and taste alterations that persist after a characterized episode of anosmia or ageusia. Case 1 to 9 reported symptoms during Step 2 and Case 10 to 13 during Step 3.

\begin{tabular}{|c|c|c|c|c|}
\hline Gender & Age Years & $\begin{array}{c}\text { Anosmia Duration } \\
\text { Days }\end{array}$ & $\begin{array}{c}\text { Ageusia Duration } \\
\text { Days }\end{array}$ & $\begin{array}{c}\text { Persistent Qualitative Alterations of Smell or Taste or Phantosmia } \\
\text { Reports }\end{array}$ \\
\hline 1. M & 38 & 20 & 20 & Odours and tastes are still slightly different. Persistent ageusia for subtle \\
2. M & 24 & 25 & 25 & flavours. \\
& & 10 & 150 & No disgust but need to salt the dishes a little more. \\
\hline 3. F & 65 & 14 & 14 & I need to salt the dishes a little more. \\
4. F & 16 & 21 & 45 & Cheese, yogurts and fruit juices taste different. \\
5. F & 30 & 30 & Disgust for carrots. \\
6. F & 69 & & & Carbonated drinks were different. Red wine is still very bitter. \\
\hline
\end{tabular}




\begin{tabular}{|c|c|c|c|c|}
\hline 7. $\mathrm{M}$ & 41 & 40 & 40 & $\begin{array}{l}\text { Food smell was not different, but the smell of dishwashing soap was differ- } \\
\text { ent. I had very frequent olfactory hallucinations, especially strong smells of } \\
\text { cooking and cold tobacco. }\end{array}$ \\
\hline 8. F & 41 & 4 & 2 & $\begin{array}{l}\text { The bad smells were reduced by } 80 \% \text { and the food lost more than half its } \\
\text { intensity in taste. Almost non-existent coffee smell. Tingling sensation in the } \\
\text { nose. Disgust for meat. }\end{array}$ \\
\hline 9. F & 42 & 90 & 30 & $\begin{array}{l}\text { Everything is different. I've recovered my sense of smell, but not like before, } \\
\text { and there are things I don't feel. I got the taste back but not like before and } \\
\text { there are some things I can't define. }\end{array}$ \\
\hline $\begin{array}{l}\text { 10. } \mathrm{M} \\
11 . \mathrm{F}\end{array}$ & $\begin{array}{l}26 \\
31\end{array}$ & $\begin{array}{l}14 \\
14\end{array}$ & $\begin{array}{c}14 \\
0\end{array}$ & $\begin{array}{l}\text { I have chemical and moldy ghost smells. } \\
\text { I feel that my general sense of smell remains diminished. Cooking smells are } \\
\text { less definable than before and I no longer perceive certain smells. }\end{array}$ \\
\hline 12. F & 42 & 18 & 0 & $\begin{array}{l}\text { I still have a loss of smell for certain smells, I no longer perceive the bad smell } \\
\text { and I have ghost smells. }\end{array}$ \\
\hline 13. F & 37 & 15 & 8 & I no longer perceive the burnt or the bad smells. \\
\hline
\end{tabular}

In the present study, anosmia was reported in $79 \%$ of cases with a mean duration of 12 days, and ageusia in $72.8 \%$ of cases with a mean duration of 13 days. Approximately $1 / 5$ and $1 / 4$ of participants considered they had not fully recovered the sense of smell and taste three months after COVID-19 onset. Thirteen subjects reported persistent qualitative alterations, which lasted for more than eight months in four cases. According to this study, subjects who had a long initial episode of anosmia or ageusia, on average 3 weeks or more, were more likely to have persistent qualitative disorders of smell and taste such as dysosmia, phantosmia, dysgeusia and food disgust. Ghost smell included strong smells of cooking and cold tobacco, nasal stinging, chemical and mouldy sensations. Two subjects described a new and persistent disgust for carrots and meat. The main limitations of this study are the participants' selfreported answers, the low SARS-CoV-2 testing rate and the limited cohort size with decreasing number of participants from Step 1 to Step 2 and 3 [4,18,19]. However, the results are within the range of previous studies in Europe and in the U.S.A. For instance, in Italy [5]. observed $73.6 \%$ of anosmia or ageusia symptoms in a series of 72 patients treated in hospital [5]. Lechien et al. [6] reported anosmia (85.9\%) and ageusia (88.0\%) in 417 patients recruited in France, Belgium, Italy and Spain, who suffered from mild-tomoderate forms of the disease [6]. Yan et al. [7], reported smell and taste loss in $68 \%$ and $71 \%$, respectively, of 59 patients in California [7]. In a series involving 60 inpatients in Iran, $98 \%$ of patients exhibited some smell dysfunction [20]. In contrast, Mao et al. [20] reported a very low prevalence of anosmia (5.1\%) and ageusia (5.6\%) in a retrospective study including 214 hospitalized patients in Wuhan, China, where the pandemic was initially described [20]. In Singapore, China, Wee et al. [18] reported $22.7 \%$ of olfactory or taste disorders in a series of 154 patients [18]. Therefore, the prevalence of anosmia or ageusia in COVID-19 patients in China ranges from $5 \%$ to $22 \%$, while it is approximately from $70 \%$ to nearly $100 \%$ in other countries. To this day, difference between China and other countries remains unexplained. However, in this study, patients could be split in two categories: those describing a cranial evolution (anosmia/ageusia/phantosmia), and those describing an oropharyngeal evolution(sore throat, cough). Differences between China where face masks are commonly used and other countries could be explained by the route of virus transmission [21].

Clinical evolution of COVID-19 could not be related to anosmia or ageusia. However, anosmia showed a strong association with BMI $\geq 25$ (overweight). Previous studies showed that ablation of a neuronal cilia marker, type 3 adenylyl cyclase, can cause obesity in mice [22]. Although other ciliopathies such as Kallman's syndrome are associated with anosmia and obesity Sarfati et al. [23], mechanisms for anosmia in overweighed or obese patients remain uncertain. Validated tests are available for the diagnosis of anosmia, and another limit of the present study is that anosmia and ageusia symptoms were not detailed [20]. However, questions such as tobacco smoking, runny nose or dry mouth eliminated some potential sources of bias. In this limited cohort study, dysosmia, phantosmia, dysgeusia and food disgust seemed randomly attributed to different neurosensorial and sensitive pathways (Table 3). Participants reported persistent alterations related to olfaction (volatiles odorous molecules/cooking, cold tobacco, burnt: $1^{\text {srt }}$ pair of cranial nerves or I), taste stricto sensu (sweet/carrots, fruit juice; bitter/wine, coffee; acid/yogurt, fruit juice; salty; umami/cheese, meat: VII sensory root, IX and X), and chemosensory stimuli (pungent stimuli/ tingling sensation in the nose, carbonated drinks; astringent stimuli/wine tannins: $V_{3}$ ). These results confirm that some taste alterations could not be attributed exclusively to olfactory epithelium infection, but also to gustatory and chemesthesis alterations [13]. The maxillary branch of trigeminal nerve $\left(\mathrm{V}_{2}\right)$ involved in heat, cold, tact, pain $\left(\mathrm{V}_{2 \text { - }}\right.$ ${ }_{3}$, IX and $\left.\mathrm{X}\right)$ and temporomandibular proprioception $\left(\mathrm{V}_{2-3}\right)$ seems preserved. In this study, the mean duration of anosmia and ageusia symptoms (12-13 days) is compatible with a regeneration of neurons and supporting cells (10 days), which suggests that most of SARS-CoV-2 infections don't reach the olfactory bulb. In contrast, persistent symptoms of dysosmia, phantosmia and dysgeusia $(\geq 3$ weeks) could be related to a brain infection [10]. Further studies of longer duration and involving larger cohorts are needed, in 
particular to monitor the disappearance of symptoms. In this work $5 \%$ of participants presented with taste and smell disorders that persisted for more than 8 months. The arrival of COVID-19 vaccines will reduce the number of new cases, but with more than 67 million people infected to date, it can be estimated that several hundred thousand people will suffer from persistent anosmia and ageusia following the 2019-2020 pandemic. Smell and taste alterations can lead to excessive or default hygiene disorders, decreased libido, stress due to loss of danger signals ("poisoned" or moldy foods, fire, chemicals), loss of appetite, weight loss and depression [17]. After SARS-CoV-2 infection, health professionals and the general public need to be aware of these risks in order to better anticipate and treat them.

\section{Conclusion}

Taste and smell impairments can last several months after COVID-19. Persistent anosmia and ageusia can lead to nutrition disorders and depression, and should be monitored after a COVID-19 episode.

\section{Conflict of Interest}

None to declare.

\section{Funding}

This research did not receive any specific grant from funding agencies in the public, commercial, or not-for-profit sectors.

\section{References}

1. Machhi J, Herskovitz J, Senan A, Dutta D, Nath B, et al. (2020) The natural history, pathobiology, and clinical manifestations of SARS-CoV-2 infections. J Neuroimmune Pharmacol 15(3): 359-386.

2. Riggioni C, Comberiati P, Giovannini M, Agache I, Akdis M, et al. (2020) A compendium answering 150 questions on Covid-19 and SARS-CoV-2. Allergy 75(10): 2503-2541.

3. Sato T, Ueha R, Goto T, Yamauchi A, Kondo K, et al. (2020) Expression of ACE2 and TMPRSS2 proteins in the upper and lower aerodigestive tracts of rats: Implications on Covid-19 infections. Laryngoscope, pp. 1-17.

4. Giacomelli A, Pezzati L, Conti F, Bernacchia D, Siano M, et al. (2020) Selfreported olfactory and taste disorders in patients with severe acute respiratory coronavirus 2 infection: A cross-sectional study. Clin Infect Dis 71(15): 889-890.

5. Vaira L, Deiana G, Fois A, Pirina P, Madeddu G, et al. (2020) Objective evaluation of anosmia and ageusia in Covid-19 patients: Single-center experience on 72 cases. Head Neck 42(6): 1252-1258.

6. Lechien JR, Chiesa-Estomba C, De Siati D, Horoi M, Le Bon S, et al. (2020) Olfactory and gustatory dysfunctions as a clinical presentation of mildto-moderate forms of the coronavirus disease (Covid-19): A multicenter European study. Eur Arch Otorhinolaryngol 277(8): 2251-2261.
7. Yan CH, Faraji F, Prajapati D, Boone C, DeConde A (2020) Association of chemosensory dysfunction and Covid-19 in patients presenting with influenza-like symptoms. Int Forum Allergy Rhinol 10(7): 806-813.

8. Mao L, Jin H, Wang M, Hu Y, Chen S, et al. (2020) Neurologic manifestations of hospitalized patients with coronavirus disease 2019 in Wuhan, China. JAMA Neurol 77(6): 683-690.

9. Doty RL (2019) Treatments for smell and taste disorders: A critical review. Handb Clin Neurol 164: 455-479.

10. Slankster E, Odell S, Matthew D (2019) Strength in diversity: functional diversity among olfactory neurons of the same type. J Bioenerg Biomembr 51(1): 65-75.

11.Zubair A, McAlpine L, Gardin T, Farhadian S, Kuruvilla D, et al. (2020) Neuropathogenesis and neurologic manifestations of the coronaviruses in the age of coronavirus disease 2019: A Review. JAMA Neurol 77(8): 1018-1027.

12. Bilinska K, Butowt R (2020) Anosmia in Covid-19: A bumpy road to establishing a cellular mechanism. ACS Chem Neurosci 11(15): 21522155.

13. Parma V, Ohla K, Veldhuizen M, Niv M, Kelly C, et al. (2020) More than smell-Covid-19 is associated with severe impairment of smell, taste, and chemesthesis. Chem Senses 45(7): 609-622.

14. Wang Z, Zhou J, Marshall B, Rekaya R, Ye K, et al. (2020) SARS-CoV-2 receptor ACE2 is enriched in a subpopulation of mouse tongue epithelial cells in nongustatoy papillae but not in taste buds or embryonic oral epithelium. ACS Pharmacol Transl Sci 3(4): 749-758.

15. Vincis R, Fontanini A (2020) Central taste anatomy and physiology. Handb Clin Neurol 164: 187-204.

16. Romero-Sanchez C, Diaz-Maroto I, Fernandez-Diaz E, Sanchez-Larsen A Layos-Romero A, et al. (2020) Neurologic manifestations in hospitalized patients with Covid-19: The ALBACOVID registry. Neurology 95(8): e1060-e1070.

17. Kohli P, Soler Z, Nguyen S, Muus J, Schlosser R (2016) The association between olfaction and depression: A systematic review. Chem Senses 41(6): 479-486.

18. Wee L, Chan Y, Teo N, Cherng B, Thien S, et al. (2020) The role of selfreported olfactory and gustatory dysfunction as a screening criterion for suspected Covid-19. Eur Arch Otorhinolaryngol 277(8): 2389-2390.

19. Hopkins C, Surda P, Kumar N (2020) Presentation of new onset anosmia during the Covid-19 pandemic. Rhinology 58(3): 295-298.

20. Moein ST, Hashemian S, Mansourafshar B, Khorram-Tousi A, Tabarsi P, et al. (2020) Smell dysfunction: A biomarker for Covid-19. Int Forum Allergy Rhinol 10(8): 944-950.

21. Xiong L, Li J, Xia T, Hu X, Wang Y, et al. (2018) Risk reduction behaviors regarding $\mathrm{PM}_{2.5}$ exposure among outdoor exercisers in the Nanjing metropolitan area, China. Int J Environ Res Public Health 15(8): 1728.

22. Qiu L, Le Bel R, Strom D, Chen X (2016) Type 3 adenylyl cyclase: A key enzyme mediating the camp signaling in neuronal cilia. Int J Physiol Pathophysiol Pharmacol 8(3): 95-108.

23. Sarfati J, Dodé C, Young J (2010) Kallmann syndrome caused by mutations in the PROK2 and PROKR2 genes: Pathophysiology and genotype-phenotype correlations. Front Horm Res 39: 121-132. 